\title{
THE BASEMENT FAULTS SYSTEM IN THE NORTHWESTERN ARABIAN PLATE, JORDAN
}

\author{
Al-Zoubi A. S. ${ }^{1}$ \\ 'Al-Balqa' Applied University, Faculty of Engineering, Surveying and Geomatics Department, \\ Salt, Jordan Al-Salt, 19117 Jordan, aalzoubi@go.com.jo
}

\begin{abstract}
Gravity and magnetic data are powerful tools utilized to detect the faults (lineaments). In Jordan, still the detailed analyses and reprocessing based on images, would effectively generate shaded relief of second derivative of potential filed, as the contour gravity and magnetic maps itself yield additional faults location. Accordingly new basements faults map focuses on faults crisscrossing Jordan that scrutinize the structural condition of Jordan indicating that the faults belong to distinct groups with different directions. However, these groups are representing a system of an "Orthogonal and Diagonal" network deem to be part of the pragmatic fracture system of the earth. It has been observed that the striking characteristics of these faults expressed by their (1) faults extension relatively extended for long distances and (2) intersection of these systems with each other possibly will help in defining their relative ages. Comparing the results of the current study with those of previous investigations provide an evidence to deem that these known faults in Jordan as supported by the geological or geophysical studies coincide in their positions with faults of linear characteristics as the new interpretation of the potential field maps indicates. However, a single system of this network shows a group of identical characteristics, as each system was formed at the same period of time, yet these different fault systems are concordant with the different phases of the tectonic activities of the region.
\end{abstract} Key words: Potential Field, Dead Sea, Shaded Relief, Pragmatic Fracture.

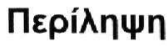

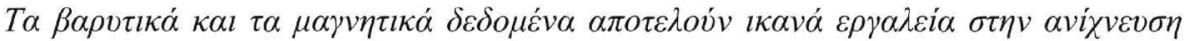

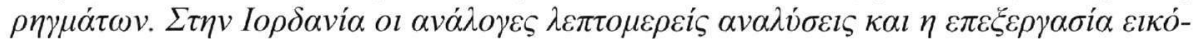

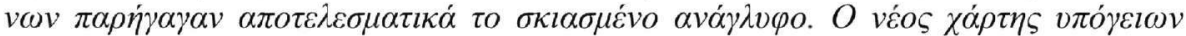

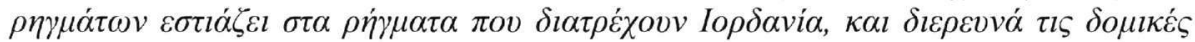

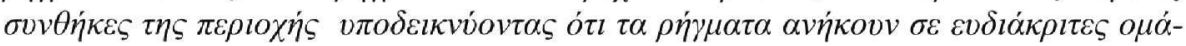

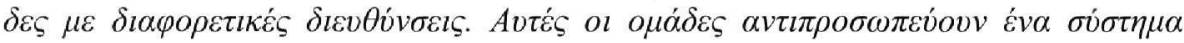

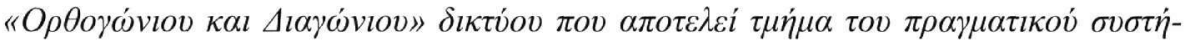

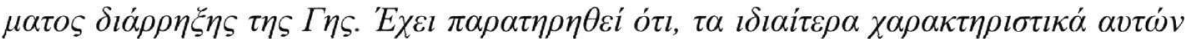

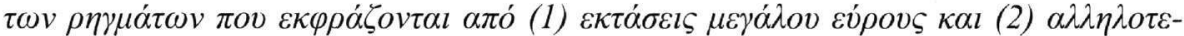

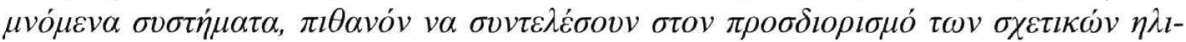

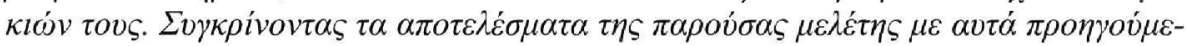

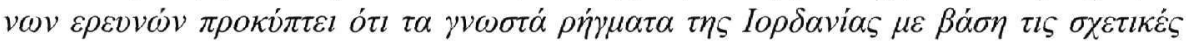

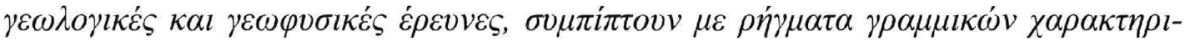




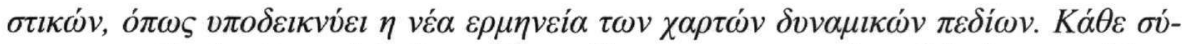

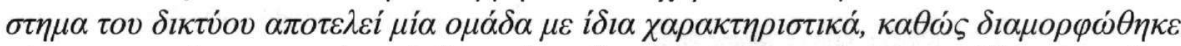

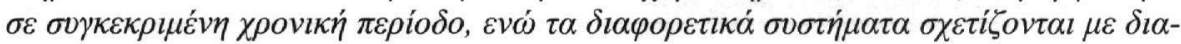

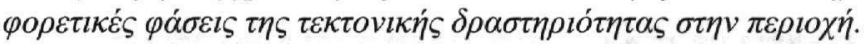

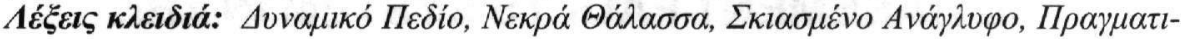
$\kappa o ́ \varsigma T \varepsilon \mu \alpha \chi \imath \sigma \mu o ́ \varsigma$.

\section{Introduction}

Jordan is situated at the northwestern side of the Arabian Plate, along the eastern flank of the ancient Tethys Ocean in the western side of the Dead Sea Transform (Fig. 1). Dead Sea Transform extends for more than $1000 \mathrm{~km}$ from the northern end of the Red Sea, where the crust is currently extending to the Taurus zone plate collision in Europe (Fig. 1). Eversince the time of its formation, less than $20 \mathrm{My}$ ago, the Dead Sea Transform Fault has undergone about $105 \mathrm{~km}$ left-lateral horizontal displacement (Joffe and Garfunkel 1987, Freund et al. 1970, Garfunkel 1981, Hatcher et al. 1981 Quennel 1958, Girdler 1985), leading to have Jordan situated at the transition zone between the stable part of the Arabian Plate and the unstable area of the Dead Sea Transform Fault. Lovelock (1984) suggested that the crust in the northwestern part of the Arabian Plate (beneath Jordan) has been fragmented into stable blocks separated by mobile zones. While the crystalline basement and sedimentary cover holds a block structure with faults to serve as blocks boundaries. Despite of its significant geodynamic settings, the Jordan block structure and its boundaries has been subjected to limited investigation. Although several studies on the sedimentary basin of Jordan have been conducted, most of these tend to focus on the large basins such as Dead Sea, Al-Azraq, Wadi Sirhan, El Jafer and Risha Basin (Fig. 2) particularly in reference to oil exploration which were largely based on seismic investigation. These studies are still limited and inaccessible to public for further evaluation.

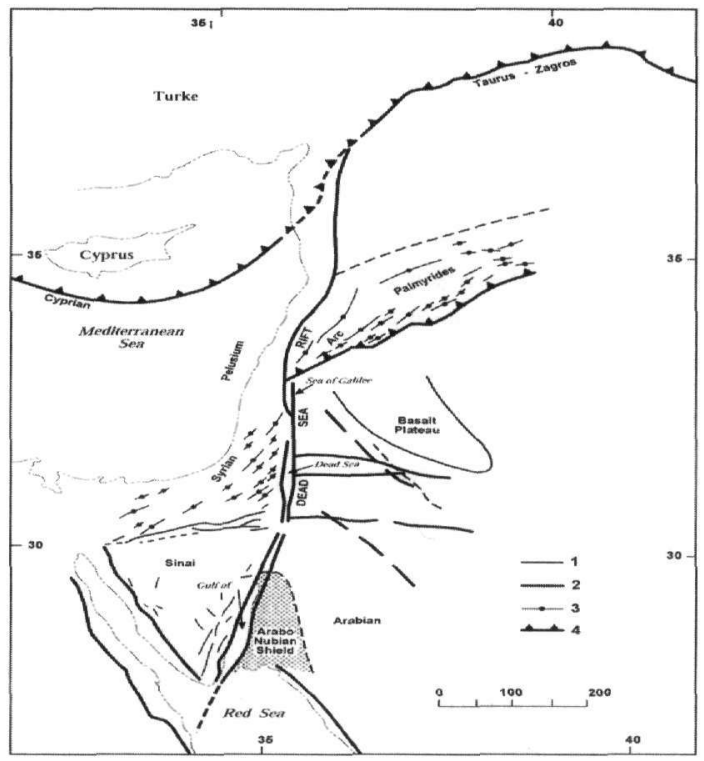

Figure 1 - Generalized tectonic setting of the Middle East showing the Arabian plate, Sinai sub-plate, the Dead Sea Transform (including Gulf of Aqaba, Dead Sea, and Sea of Galilee) and Palmyrides zone. 1-Faults; 2-Main Faults; 3-Fold Axes; 4 -Main Thrust Fronts (modified after Ben-Avraham and Grasso 1991, Bender 1974) 
The Northwestern Arabian block (Jordan) has been generally regarded as structurally featureless, except for a few well-acknowledged faults. Jordan Geological Map (modified after Bender 1968) displayed only few sets of faults (Fig. 3) trending N-S and NW-SE and E-W striking short faults in the central part of Jordan. The significance of these faults is due to the fact that they control the mineral deposits, oil and gas within several sedimentary basins and groundwater flows. Similarly, there are other natural resources (mineral deposits, hydrocarbon and groundwater flow) scattered at various geologic sites associated with fluid conducting faults.

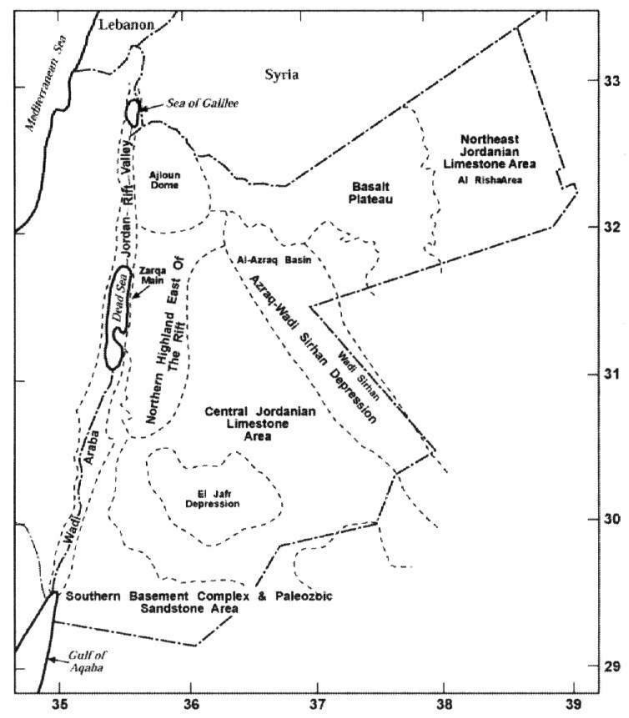

Figure 2 - Geologic-physiographic provinces of Jordan (after Bender 1974)

Therefore in order to detect subsurface faults more precisely, geophysical methods are considered as a powerful tool, i.e., potential methods (gravity and magnetic) or seismic process.

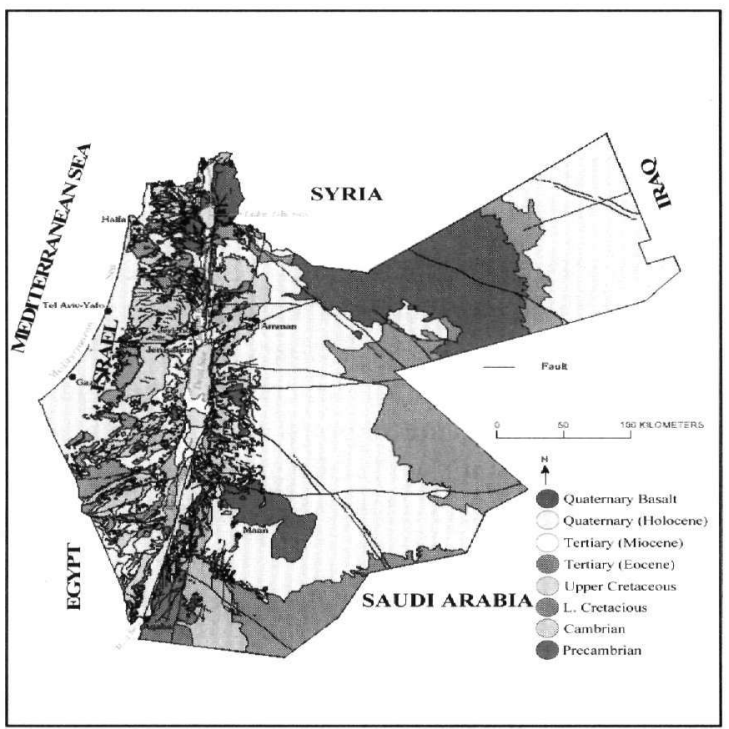

Figure 3 - Regional Geology map of Jordan

The present study utilizes potential field methods over a broad region as an attempt to describe the faults structure of Jordan. The steep basement faults in Jordan platform tends to be more subtle and 
exerts a considerable Syn-and Post-depositional influence on the sedimentary cover. However, the faults and fractures are occasionally following the older orogenic basement structures that commonly cut across them. Nevertheless, the steep and straight faults in Jordan are commonly expressed as subtle potential-field lineaments, which might be gradient zones or alignments of separate local anomalies in various types and shapes, or aligned breaks or discontinuities in anomaly pattern.

\section{Geological Setting}

The oldest known rocks of Jordan, classified as a Pre-Cambrian Aqaba Granite Complex, outcrops in its southwestern part. Since the Pre-Cambrian age the granitic shield is predominantly a land surface ringed by seas receiving sediment from the land. Generally, Jordan tectonic history is divided into three phases: the Gondwana, Syrian Arc, and Rift phases (Dewey et al. 1973). During the Gondwana phase (Cambrian - Early Cretaceous), Jordan was on a spot near the northern margin of the Gondwana paleo-continent. Tectonically, the area was relatively stable and the sedimentation was dominantly continental type, interspersed with rather minor but widespread marine incursions. However, the Lower Palaeozoic rocks of Cambrian, Ordovician and Silurian age are outcropping in southern Jordan and on the western side of the Dead Sea-Jordan Rift Valley. Several wells have encountered Upper Carboniferous and Permian rocks of the pre-rift sequence, indicating a variety in depositional environments from continental clastic to shallow marine carbonate. In fact, this general sedimentation pattern continued into the Triassic and Early Jurassic, yet its sedimentation became increasingly more aquatic. The shoreline position from Triassic to Late Cretaceous remained roughly unchanging across central Jordan with the open sea lying to the northwest.

During the Late Cretaceous, it has been noticed that subduction of the Neo-Tethyan oceanic lithosphere was initiated at the north. Whereas, the resulting compression along the southern margin of the Neo-Tethys indicated within locally abducted ophiolites and folding in the Syrian Arc trend. The Syrian Arc portrays a sigmodial trend extending from the northern Sinai northward into Syria (Fig. 1), following to the trend of the Late Cretaceous continental margin. However, the extension within the Arabian Plate during the Late Cretaceous (Bender 1974, Lovelock 1984) caused a series of northwest-trending basins such as Al-Azraq and Wadi Sirhan Basins (Fig.2). At later stages, a strike-slip faulting in the Neogene's have modified the overall configuration and structural style of the Al-Azraq and Wadi Sirhan Basins, then offset and modified the fold geometry of the Syrian Arc trend. Various transgressions from the northwest to the southeast were repeated several times during the Mesozoic. Moreover, between the middle Jurassic and Early Cretaceous the volcanism was active in the western part of Jordan. Likewise a mafic to felsic dykes and sills occurred in the Wadi Araba region are cutting across the Mesozoic sedimentary rocks (Bender 1974).

During the Late Oligocene - Early Miocene, the left lateral movement along the Dead Sea - Jordan Rift Valley was initiated along with coarse lenticular unsorted conglomerates which begin to appear in the section overlying Late Cretaceous or Tertiary units in the eastern Wadi Araba area. However, they show unconformable relationship at several localities indicating uplift and probably tectonic activity (Bender 1974). Therefore, the regional fault system consists of a series of three major west-stepping, en-echelon faults, with well defined pull-apart basins having formed at each of the major offshoots, i.e., the Gulf of Aqaba, Dead Sea Basin and Sea of Galilee Basin (Figs 1, 2).

An apparent total strike-slip displacement along the Dead Sea Rift system estimated at $105 \mathrm{~km}$ (Freund et al. 1970). Matching the structural and sedimentary features offset across the fault zone, Quennel (1958) considered that the separation took place at two stages; the first stage expanding to $63 \mathrm{~km}$ took place during the Miocene, whereas the second stage took place during the late Pleistocene. Furthermore, Garfunkel (1981) and Freund et al. $(1976,1970)$ have reached a similar conclusion through measuring a contemporaneous motion in the adjoining Red Sea. They recommended that the second stage should have taken place 4-5 My ago leading to the Dead Sea Rift 
opening whereas more than $3.5 \mathrm{~km}$ of evaporites were deposited, probably during the late Miocene to early Pleistocene (Bender 1974). The total basin fill within the Dead Sea basin reaches more than $10 \mathrm{~km}$ (Ginzburg and Ben-Avraham 1997). Measurements based on gravity data, and the Dead Sea basin represent a long pull- apart nature of $135 \mathrm{~km}$ long, 10-20 km wide (ten-Brink et al. 2001, 1999, 1993) and at least $8.5 \mathrm{~km}$ deep. Some localities show $7.250 \mathrm{~km}$ Pliocene salts (AlZoubi and ten-Brink 2001). Consequently, Al-Zoubi and ten-Brink (2001) estimated the thickness of the original salt layer to be not less than $2.3 \mathrm{~km}$.

The deposits of Quaternary age in Jordan reflect a continuous uplifting and retreating of the marine environment, with an extensive mafics volcanic and shallow intrusive activity occur as localized flows and plugs. The plateau flood basalts with primitive chemistry appear to reflect a rapid propagation of fractures into the mantle, followed by rapid extrusion (Barberi et al. 1979). Based on the geological history described above and other geological, paleogeographic and stratigraphic evidence, the territory of Jordan can be subdivided into seven major geological-physiographic provinces as given in Figure 2.

\section{Geophysical Data}

The sedimentary basin in Jordan has been explored and investigated over the last four decades. Numerous land magnetic, gravity and seismic surveys were carried out as a part of oil exploration in the region. Gravity data in Jordan were compiled by the Natural Resources Authority, summarized from various surveys recorded at different times using different parameters, technologies and specifications. Considerably, the gravity-data standards of one station per $4 \mathrm{~km}$ are usually maintained in remote areas of Jordan, whereas the lineaments with enough length are detectable with careful anomaly enhancement. In addition, the aeromagnetic survey was completed in the 1981 along grid flight lines in EW and NS directions. The geophysical data in some places were supplemented by borehole data which provided valuable information about a complex architecture of the basins. To refine the techniques of detecting faults we have created a magnetic and gravity maps of Jordan, with the data processed to highlight subtle lineaments. The new maps are correlated with the geological maps (scale 1:50.000) in particular those may be related to brittle faults.

\section{Magnetic Map}

The aeromagnetic map of Jordan (Fig. 4) is dominated by large amplitude, low frequency anomalies expect in a few areas. Recording a strongly contrasting pattern of short wavelength and high frequency anomalies of low amplitude related to surface mafic rocks (basalt) which are highly magnetic occurring east of the Dead Sea in the northeast Jordan. The central, southeastern and eastern part of Jordan tends to produce mostly broad relatively long wavelength anomalies reflecting the thick sedimentary section.

Apparently, the magnetic map of Jordan has a relatively smooth relief except where it reflect the basalt flow. However, there are some large anomalies located in the southwestern, northwestern and central part of Jordan. The anomaly located in the SW Jordan is sharply terminated to the west and linked to the shallow faulted basement. The series of round to elliptical (high and low) in shape anomaly formed lines which facilitate the process of correlating them with the faults. Similarly, an identical shape occurred along Al Karak-Wadi Fiha fault. In the central part of Jordan the low magnetic anomaly strikes about EW and extends across it. It bifurcates eastward, north and south of a large high magnetic anomaly which terminates in east central Jordan and continues eastward into Saudi Arabia (Phoenix 1981). It is worth mentioning that some local intrasedimentary anomaly sources could be in relevance to depositional concentrations of magnetic minerals. However, in some clastic rocks or in secondary magnetization of sedimentary rocks derived from the circulating brines or the surface's man-made infrastructure may also cause anomaly. 


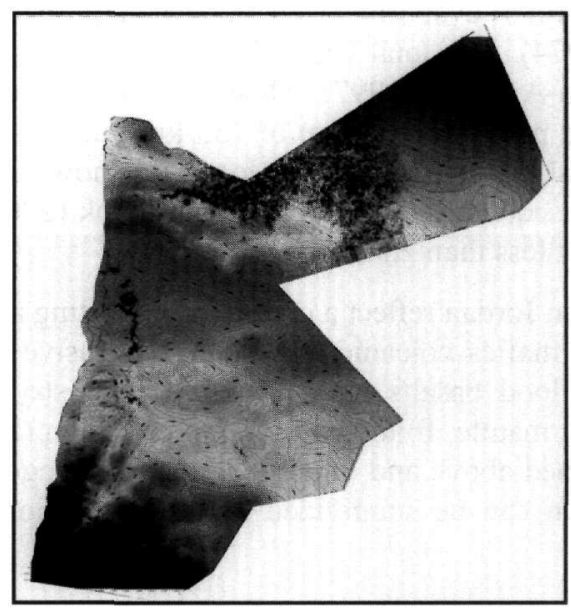

Figure 4 - Total field magnetic map of Jordan (Phoenix 1981). Contour interval is $10 \mathrm{nT}$

\section{Gravity Map}

The Bouguer gravity map of Jordan (Fig. 5) outlines large-scale of variations, a difference of 136 $\mathrm{mGal}$ was recorded, whereas several trends and anomalies are clearly observed on the Bouguer anomaly map including the followings: (1) north-northeasterly trend gravity anomalies of the order of -20 to $-132 \mathrm{mGal}$ were marked at Wadi Araba- Dead Sea- Jordan Valley Rift. The northern parts of the Wadi Araba-Dead Sea-Jordan Valley Rift area dominated by small variations ranging from -20 to $-30 \mathrm{mGal}$, while moderate variations ranging from -50 to $-85 \mathrm{mGal}$ were marked in the southern parts. The Bouguer gravity anomaly decreases gradually from both northern and southern parts of the Wadi Araba -Dead Sea- Jordan Valley Rift towards the Dead Sea Basin, suggesting that the Dead Sea Basin sags towards the center (ten-Brink et al. 1993, Al-Zoubi and tenBrink 2002). The lowest Bouguer gravity value was recorded is $-134 \mathrm{mGal}$; (2) the existence of a north-northeasterly trend gravity anomalies, of the order of -35 to $+4 \mathrm{mGal}$ are marked the northern Highlands east of the Rift. The anomaly as high as $+4 \mathrm{mGal}$ follows the elevated topography of Ajloun uplift. Ajloun uplift is a broad domal structure covered by $4-5 \mathrm{~km}$ of predominantly Mesozoic sedimentary strata. However, a model for crust underneath the northern highland shows that the crust is marked with higher density and thicker than that of the transform zone area on the western side. The northeastern plateau on the eastern side indicates that Jordan may have been affected by orogenic processes which have resulted in densification of the crust (Al-Zoubi and Ben-Avraham 2002); (3) a northeast trend of nearly narrow zone high gravity anomalies -40 mGal, is marked the Southern Basement Complex; (4) the high Bouguer gravity anomaly lies in the northwestern part of the Central Jordanian Limestone Area. The anomaly is roughly oval shaped and marked by $-18 \mathrm{mGal}$ Bouguer gravity high; (5) a south- southeast negative gradient in regional Bouguer values from $-60 \mathrm{mGal}$ to $-95 \mathrm{mGal}$ in the southern parts of the Central Jordanian Limestone Area. The negative gradient follows the Tabuk basin in Saudi Arabia; (6) within the area Al-Azraq- Wadi Sirhan Depression, the gravity field ranges from -55 to $-80 \mathrm{mGal}$ and maintains a general northwesterly trend; and (7) a northeast positive gradient in regional Bouguer values from $-60 \mathrm{mGal}$ in the southern parts of the Northeast Jordanian Limestone Area to $-50 \mathrm{mGal}$ in the northeast side and the region northeast of the Basalt Plateau. The positive gradient follows Rutbah uplift in the southeastern parts of Syrian and western Iraq. Remarkably, the Rutbah uplift is a broad domal basement structure covered by $5-6 \mathrm{~km}$ of predominantly Palaeozoic sedimentary strata (Al- Zoubi 1992). 


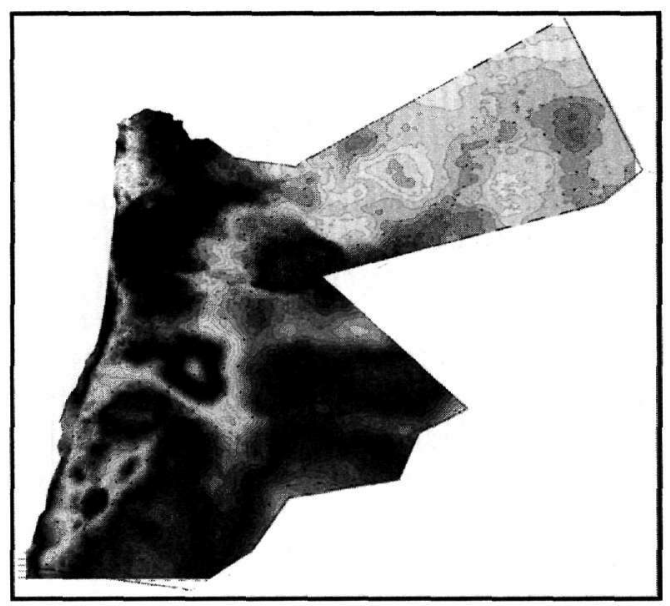

\section{Figure 5 - Bouguer Gravity Map of Jordan (Natural Resources Authority), contour interval 2 mGal}

\section{Data Preparation}

To trace the faults' signatures within a magnetic and gravity maps detailed data processing using a wide variety of anomaly-enhancement techniques and display parameters is essential. The best way is to sort potential anomaly by shape, amplitude, trend and other relevant geological features. However, this is considered as a critical process as some short wave length anomaly produced artificial sources could interfere with geological features. Therefore, the false anomaly (noise) should be suppressed prior to processing. The filtering process or upward data continuation helped to remove the shortwave anomaly and smoothed the data.

The diversity of filtering techniques has been applied to the analyses of potential field data. However the recognition should be to the traditional methods of presentation, principally contour maps, which filter-out much of the original information content of the data connected to geological structure and trend. Therefore, filters have proved effective forms of presentation particularly for regional data. Filters contain data about both anomaly amplitude and anomaly gradient (relief), exploited the inherent ability of the human visual system to interpret intensity and textural information. The latter is significant, particularly as anomaly gradients trend directly to the depth of burial of the causative structures. Nevertheless, the shaded-relief presentations are significance to treat the field as topography illuminated from a particular direction. Possess an additional property of enhancing features which trend roughly perpendicular to the direction of illumination having a sense of enhancing subtle, but often important to lineaments which were not apparent on the original contour maps.

\section{Geophysical Fault Detection}

The interpretation stage carried out by subdividing Jordan into different zones according to morphology and the level of homogeneity of the magnetic and gravity fields. The magnetic and gravity maps of Jordan shown in (Figs 4, 5) were subdivided into almost homogeneous zones. These zones were sort in accordance with the geological overview of Jordan, particularly with the magnetic contour map (Fig. 4) which clearly shows borders of these zones (Figs 2, 3). The quality of interpretation basically based on the conventional contour maps of the potential field data including total intensity of magnetic map (Fig. 4), Bouguer gravity map (Fig. 5) shaded relief maps of Bouguer gravity (Fig. 6), shaded relief of magnetic map (Fig. 7) and magnetic image map (Fig. 8). 
Best visual method to identify lineaments is to view the map in different angles, to view with different orientations. The linear anomaly extends for hundreds of kilometres easily, which could be related to the major faults that are cutting the earth crust. These anomalies are clearly seen at the central, southern and northeastern parts of Jordan (Figs 4-8).

Figure (9) shows the analyses the structural condition of Jordan indicating that these faults are within distinct groups of different directions. These groups signify an orthogonal and diagonal network system that could be considered an integrated part of the regmatic fracture system of earth. Each group of the orthogonal and diagonal network could be subdivided into two systems and consequently results in four sub-systems of main faults as following: (1) N-S direction faults; (2) NW-SE direction faults; (3) E-W direction faults; and (4) NE-SW direction faults. However, the striking characteristics of each of these faults are: (1) an extension of the faults relatively expanding for long distances and (2) intersection of these systems with each other may help in the determining their relative ages.

\section{Structural Interpretation}

Comparing the results of the current geophysical study with previous investigations indicates that the identified faults in Jordan coincide in their positions with faults of linear characteristics which were defined as a result of the interpretation of potential field maps. A single system of this network displays a group of identical characteristics, taking into account that each system was formed under certain stress of conditions. However, it is possible to be reactivated under different stress fields in different phases of the tectonic activities of the region. Moreover, the distances between faults of a signal system depends on their courses and structures type that intersect them.

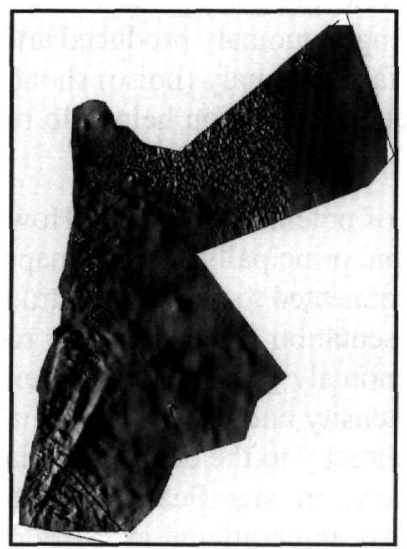

Figure 6 - Bouguer gravity map shaded relief, Jordan

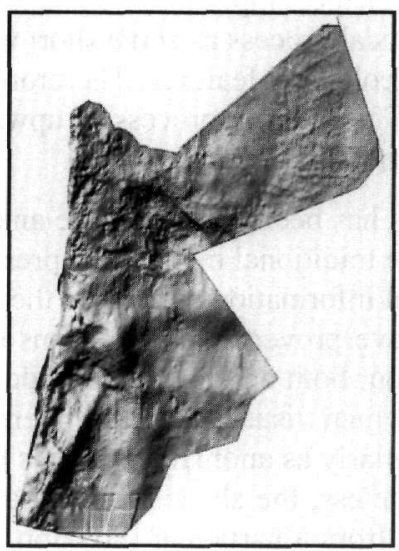

Figure 7 - Magnetic map shaded relief, Jordan

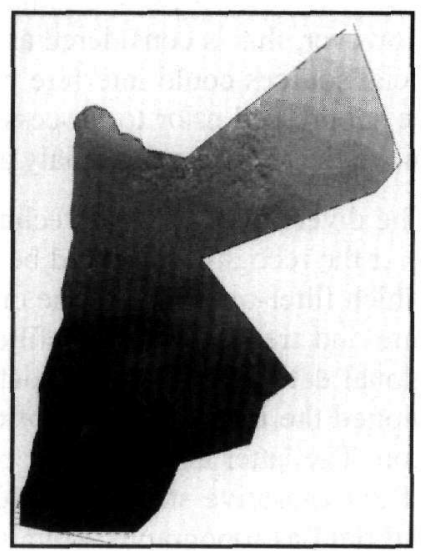

Figure 8 - Image of the total magnetic field map, Jordan

The performed geophysical evaluation of the fault pattern mainly refers to the deformation pattern which exists within the upper rock cover; nonetheless, more than $80 \%$ of Jordan is covered by rocks younger than Jurassic age. Indicating that tectonic activities of Cretaceous age up to the Quaternary are responsible for what might be seen on the surface and in outcrops. Although, few structural patterns are tracing pre-existing tectonic elements from the deeper older rock formation, these are not indicating that the pre-existing structures have not affected the recent deformation patterns in the younger sediments. On the contrary, they should have been reactivated due to the younger deformation processes. Presume that the changing of the stress fields may have led to a reactivation impact to completely change the former character of the fault system.

The old even Precambrian structures that are trending NW-SE (Najd fault system), N-S and W-E were reactivated by the extensional forces connected to the opening of the Tethys during the Late 
Palaeozoic and Lower Cretaceous. The change from the opening of the Tethys to the subdeduction of the African-Arabian Plate; below the European-Asian Plate has led to the slightly sigmoid SW-NE trending compressional structure with folds and thrust faults. The last major tectonic deformation is caused by the N-S trending left lateral shear movement of the Arabian Plate with conjugated shear deformation.

\subsection{N-S Fault System}

This system is considered to be the major among all known fault systems, besides it is the most active system within the study area. However, one of the N-S trending faults came into sight at the eastern and central parts of Jordan which is the most pronounced pattern fitting to this system; is the Aqaba- Dead Sea- Jordan Rift system. Most of these faults are extending beyond the Jordanian territory. The fault system extends in the N-S direction tends to give a first impression of an individual successive fault zones incapacity of $12 \mathrm{~km}$ width. The separating distance of the fault zones ranging from 40 to $45 \mathrm{~km}$. Unfortunately, it was impossible to delineate such faults by the geophysical techniques, particularly in areas covered with basalts. Despite the fact that a separation of residual anomalies from regional anomalies was configuration, the lack of gravity survey data and the complexity of the magnetic anomalies map led to hinder interpretation relevant to following up faults.

Consequently, the small elongated basin character of these fault systems led to be interpreted as a continental graben system compared with the Red Sea graben as its northward continuation in a status of nascendi. However, various relevant studies have argued that this whole N-S orientated fault system is a transform structure next to the Arabian Plate that was separated from the African Plate and is moving now in a left lateral shear movement to the north. Thus, the total lateral displacements documented by the parallel offset of typical crossing structures comprehend about 107 $\mathrm{km}$.

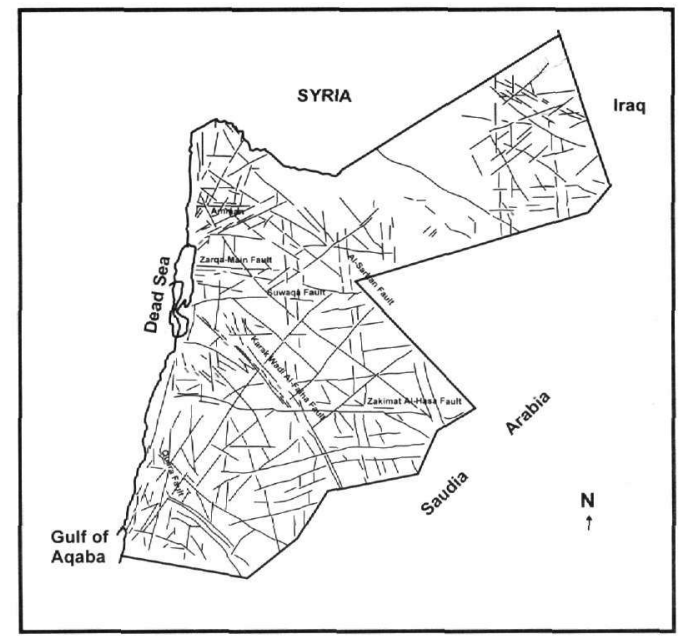

Figure 9 - Faults disruption map, Jordan

The apparent frequent isolated fault segments are belonging to through-going movement track, extending from the Red Sea towards the mountain chain in Turkey. The movement did not occur along one straight line, but jumped from one parallel shear fault to another. It was developed into a shear pattern in a narrow N-S oriented zone before the full separation of the Arabian Plate at the beginning of the shear movement. However, the left lateral movement jump from one fault to the next in the west (left side) has developed a pull-a-part basin. Meanwhile, the jump back to the east or only gradual transition or merging into the next faut in the formed a transpression zone, whargart of the northward fiving plate should be squeezed outs This pattern of pull apart basins 
and transpression zones which are required from the mechanism of the shear movement along a non-straight slightly undulated line are clearly documented over the entire area from the Gulf of Aqaba with three successive pull apart basins, unbroken in the basins of Wadi Araba, the Dead Sea Basin, the Jordan Valley Basin and the Basin of the Lake Tiberias. Transpressional zones are intercalated for instance in the area of Wadi Araba. However, this is not obvious due to young sediment cover delectable by the geophysical survey as zones with Mesozoic or basement rocks lying on shallow depths of the Wadi Araba-Jordan Rift valley.

The N-S aligned shear faults are accompanied by parallel N-S normal faults and emphasizing the $\mathrm{N}-\mathrm{S}$ fault pattern. These normal faults exemplify a secondary fault system to the transform system. Therefore, the vertical displacements along the main shear movement and particularly the steep slopes along the pull-apart basins deem to develop gravitational instabilities. This led and still leading to mass movements and vertical displacements along these normal faults pursuing a mass movement towards the Basin, partly developed on the awake of the fault steps, which for example are clearly developed along the Dead Sea.

Furthermore, the age of N-S transform system originally assumed to be a two-stage development following the former assumption of a two-stage ocean spreading in the southern Red Sea (Girdler 1985). However, the first stage with a displacement of $40 \mathrm{~km}$ has been assumed in the EoceneOligocene, while the second stage pursuing till today should have been started in the Middle Miocene. The Median Peninsula has shown that the transform movement along the Aqaba-Dead SeaJordan line was free of the opening of the Red Sea (Red Sea-Suez stage) first stage. It started about 12 My ago (Late Miocene) associated by the opening of the Gulf of Aden which in the course of ocean's spreading along the Ridge Arabia has been pushed northward since that time. Hereafter, it possible to consider that the time of the creation of some other N-S trending faults coincide with that of the Aqaba-Dead Sea-Jordan Rift ever since the late Miocene. This direction is already evident at the Precambrian basement and documented at the ascending lines of Oligocene and Early Miocene volcanism.

In addition to this, the process of quantitative interpretation of the gravity field indicates that the system extends to great depths, and the faults of this system could be considered as open faults. These types of faults are characterized by being subdivided into separate parts affected by the horizontal displacements, particularly in areas of junctions with other fault systems.

\subsection{NW-SE Fault System}

This system is composed of the NW-SE directed faults that widely distributed all over the structural map of Jordan, and extends even to the neighbouring countries such as Saudi Arabia. The extension of these faults could reach hundreds of kilometres, such as the Karak-Wadi Al-Faiha fault and Al-Sarhan faults. In general, this group of faults parallels the Red Sea Rift and penetrates the earth's crust, reaching the mantle. These faults are characterized by being originated under tensional forces (open faults). This assumption is confirmed by the occurrence of volcanic intrusions along the Karak- Wadi Al- Faiha faults, east of the Dead Sea and the great basaltic rocks covering vast area in Syria, Jordan and Saudi Arabia. The time period at which the faults of this system were originated is considered to be in accordance with the time period of which the Red Sea fault and Najd fault were generated, and mostly it is closely related to the Red Sea rift. This is obvious from the tectonic activity of these systems during the Cenozoic period, i.e., at the time when the Red Sea basin began to expand. Accordingly, it is very definite to indicate horizontal displacements in parts of this fault system that are also clearly demonstrated on the geological map of Jordan.

\subsubsection{The $E-W$ fault system}

This system includes the E-W directed faults, which have different extensions. However, some are extended even in to Saudi Arabia such as the Zakimat Al- Hasa fault. The average distance between the faults of this system is ranging from 35 to $40 \mathrm{~km}$. However, sometimes there are faults 
of relatively limited lengths (geological map of Jordan, scale 1: 500.000) for instance, the fault passes near Amman. Nonetheless, faults of this system could be considered as basement faults even though some of which are recognized on earth surface for a limited distance. It is obvious that the faults of this system have been affected by the horizontal displacement. Therefore, some of which may reach great depths such as the Zakimat Al-Hasa, Suwaqa and Zarqa-Main faults with volcanic eruptions and hydrothermal deposits.

\subsubsection{The NE-SW fault system}

Faults of NE-SW direction are shown on the geophysical maps mostly as lineaments. These linear breaks are parallel to each other and at the same time they make a curvature in the southwestern part of the country. In general, this system lies perpendicular to the Red Sea fault. In reality, the presence of this system is confirmed by the direction of wadis traces in Jordan.

\section{Discussion and Conclusions}

Considerably it is difficult to state the true age of these major fault systems in Jordan. On the other hand, scrutinizing the geological map (Fig. 3) and the map of the faults (Fig. 9) constructed in accordance to the final interpretations of the gravity and magnetic data that will allow determining the relative ages of these systems based on the relative period of the tectonic activity of these faults. Precise analyses of locations of the systems intersect in different areas indicates that the location and the intersection of the magnetic and gravity anomalies are of the same type. Whereas, the first major fault system that extends N-S could be considered as an open tension fault which is also subdivided into portions intersected by other fault systems. As the horizontal displacement is also well recognized in many parts of this system, it could be accepted as the oldest system affected by tectonic events. However, faults of the second system NW-SE underwent displacement in some locations and intersected by other fault systems as in the case of central Jordan, i.e., the Al Karak Wadi Fiha fault and the fault lying in the Wadi Sirhan and Al-Azraq Basin. These faults are considered to be open tension faults that intersect the N-S directed faults. Consequently this system could be younger than the previous one. Some elements of this system are intersected by faults of E-W direction within which lie many parts of this system. At the Conclusion, the faults of E-W direction are younger than those of NW-SE direction. The faults with NE-SW direction which were considered as lineaments are intersecting all previously mentioned fault systems. They are not affected by any displacement of its own fault portions whenever intersecting with other systems. Accordingly, this system may be considered the youngest known one as confirmed by the direction of the Wadis in the eastern and central parts of Jordan.

Examining the distribution of the faults at the structural map of Jordan, there are two perpendicular network of faults, i.e., orthogonal and diagonal. As each network consist of two systems perpendicular to each other. Commonly, each of the principal networks is considered to share the sametime-period, indicates the existence of four systems of different relative ages. It is possible to consider the age of each one of these systems only appertains to the time of the fault formation. It is possible to consider the age of the fault formation due to earth planetary jointing system which in the course of geologic times underwent changes due to many factors that were responsible for the formation of a single system within its particular characteristics as mentioned before. Therefore, the main fault systems in Jordan could be assumed as a part of the global system and its planetary characteristics.

The appearance of such systems mainly due to the rotational movement of the earth and the consequential pulses of that movement. Otherwise, it may due the diffusion of internal thermo currents and other factors to be the cause. Accordingly, Jordan presents a significant hint which let us assure two types of faults regarding their origin: (1) Displacement faults may be originated by the rotation-axial movement of earth leading to consequential pulses in stress forces and pressure in the rocks of the earth's crust and (2) Faults originated by the events of internal intrusions took place by various natural processes within the core of the earth. 
The principle role in the formation of the main fault systems is due to the changes in the rotational movement of earth and its consequential pulses that faulted the earth crust rocks and form the horizontal displacements which took place in the Afro-Arabian Rift, i.e., the strike slip movements, which in turn influenced the Arabian Plate.

\section{Acknowledgments}

The author tenure at Karlsruhe University was funded by the Alexander von Humboldt Foundation wish to thank the Jordan Natural Resources Authority of Jordan for their participation by providing accessibility to the records available relevance to this study. Furthermore, would like to extend his thanks to the Karlsruhe University (Applied Geology Department) for using their facilities and for their hospitality. Moreover, the support of Alexander von Humboldt Community is greatly appreciated.

\section{References}

Al-Zoubi, A., 1992. Deep geological structure of Jordan from geophysical data, Unpublished D.Sc. and Ph.D. Thesis, Saint Petersburg Mining Institute, Russia, 179 pp.

Al-Zoubi, A., and Ben-Avraham, Z., 2002. Structure of the earth's crust in Jordan from potential field data, Tectonophysics, 346, 45-59.

Al-Zoubi, A., and ten-Brink, U., 2001. Salt diapirs in the Dead Sea Basin and their relationships to Quaternary extensional tectonic, Marine and Petroleum Geology, 18, 779-797.

Al-Zoubi, A., and ten-Brink, U., 2002. Lower crustal flow and the role of shear in basin subsidence: an example from the Dead Sea basins, Earth and Planetary Sciences Letters, 199, $67-79$.

Ben-Avraham, Z., and Grasso, M., 1991. Crustal structure variation and transcurrent faulting at the eastern and western margins of the eastern Mediterranean, Tectonophysics, 196, 269-277.

Barberi, F., Capaldi, G., Gasparini, P., Marinelli, G., Santracroce, R., Scandone, R., and Tureil, M., 1979. Recent basaltic volcanism of Jordan and its implication on the geodynamic history of the Dead Sea shears zone, International Symposium Geodynamic Evol., of the AfroArabian Rift System, Rome.

Bender, F., 1968. Geology of Jordan, Supplement edition in English with minor revisions.

Bender, F., 1974. Geology of Jordan, Gebrueder Borntraeger, Berlin, 196 pp.

Dewey, J. F., Pitman, C.C., Ryan, W., and Bonnin, J., 1973. Plate tectonics and the evaluation of Alpine System, Geol. Soc. Am. Bull. 84, 3137-3180.

Freund, R., Garfunkel, Z., Zak, I., Goldberg, Weissbord, M. T., and Derin, B., 1970. The shear along the Dead Sea rift, Phlilos, Trans. R. Soc. London, 267 (A), 107-130.

Freund, R., and Garfunkel, Z., 1976. Guidebook to the Dead Sea rift, Hebrew University, Jerusalem, 27 pp.

Garfunkel, Z., 1981. Internal structure of the Dead Sea leaky transform (rift) in relation to plate kinematics, Tectonophysics, 80, 81-108.

Ginsburg, A., and Ben-Avraham, Z., 1997. A seismic refraction study of the north basin of the Dead Sea, Geophysical Research Letters 24, 2063- 2066.

Girdler, R., 1985. Problems concerning the evaluation of oceanographic lithosphere in the Northern Red Sea, Tectonophysics 116, 109-122. 
Hatcher, R. D., Zietz, I., Regan, R. D., and Abu-Ajamieh, M., 1981. Sinistral strike- slip motion on the Dead Sea rift: Confirmation from new magnetic data, Geology, 9, 458-462.

Joffe, S., and Garfunkel, Z., 1987. Plate kinematics of the circum Red Sea-a revaluation, Tectonophysics, 141, 5-22.

Lovelock, S., 1984. A review of the tectonics of the northern Middle East Region, Geol. Mag., $121,577-587$.

Phoenix, 1981. A comprehensive airborne magnetic/ Radiation survey of the Hashemite Kingdom of Jordan, Final Report to Natural Resources Authority, Amman.

Quennel, A. M., 1958. The structure and geomorphic evolution of the Dead Sea rift, Q. J. Geol. Soc. London, 64: 1-24.

ten-Brink, U., Al-Zoubi, A., and Rybakov, M., 2001. Bouguer gravity map of the Dead Sea fault system, Jordan and Israel, USGS, Open files report, 01-216.

ten-Brink, U., Rybakov, M., Al-Zoubi, A., Hassouneh, M., Bataeneh, A., Frieslander, U., Goldschmidt, V., Daoud, M., Rotstein, Y., and Hall, J. K., 1999. The anatomy of the Dead Sea plate boundary: Does it reflect continuous changes in plate motion? Geology, 27, 887-980.

ten-Brink, U., Ben-Avraham, Z., Bell, R., Hassouneh, M., Coleman, D., Andreason, G., Tibor, G., and Coakley, B., 1993. Structure of the Dead Sea pull-apart basin from gravity analysis, Journal of Geophysical Research, 98 (21), 887-894. 